\section{A GOOD DEATH}

\section{We need a mix of care in} the NHS

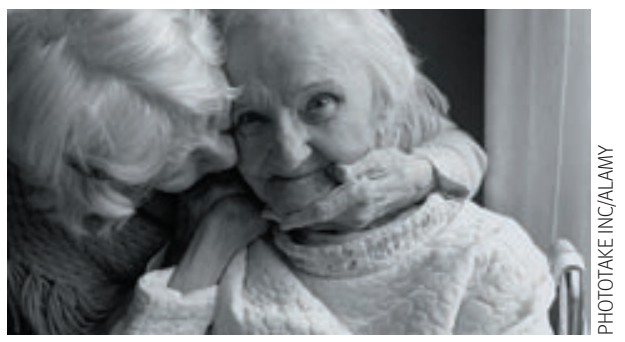

I have a similar story to Newton's about the death of my father last year. ${ }^{1} \mathrm{He}$ was 78 and for more than 20 years had seen his mobility and independence slowly eroded by multiple sclerosis. He developed a chest infection over Christmas but had strongly protested his desire to stay at home, which became impossible as pressure sores developed.

The first 11 weeks were spent in an acute medical ward. The doctors actively treated him with intravenous antibiotics, insulin infusions for diabetes, and a nasogastric tube. The emphasis was on "getting him better" so he continued to receive unpleasant active intervention despite my remonstrations that palliative care was much more appropriate. His complex illness improved, but he could not eat or look after himself: the ward was busy and he was in the wrong place. He became withdrawn and unresponsive. His pressure sores continued to get worse, and he became confused.

The last seven weeks were spent in a hospital which specialised in helping people with long term debilitating illness. Here the staff actively treated my father as a person, not as a complex medical puzzle. He was washed and shaved caringly every day; he had a haircut and had his nails trimmed. He was patiently given the type of food he was fond of. The staff sat with him and talked about his and their lives, and his confusion lifted. His pressure sores started to heal. In June he had a stroke, and he died without regaining consciousness over four days. The staff let us stay with him while he was dying and looked after us.

Both hospitals treated my father well but met different needs. The second hospital is now threatened with closure because funding is not available. We should not dispense with this type of care because targets and tariffs concentrate funding on the acute sector.

Martin G Duerden general practitioner, Meddygfa Gyffin, Conwy LL328LT martin@theduerdens.co.uk

Competing interests: None declared.

1 Newton P. A good death-but no thanks to the NHS. BMJ 2007;334:536. (10 March.)

\section{ACCESS TO RECORDS}

\section{Vulnerable people have most to lose from online access}

Richards makes a strong plea for full access to personal records online. ${ }^{1}$ However, the main danger of such access is not too much information for the patient or a threat to medical hegemony but rather to vulnerable people who may not be able to control access to the record. For example, could a mildly cognitively impaired elderly parent prevent a well meaning, but somewhat overbearing, daughter or son scanning his or her record and possibly discovering treatment for a sexually transmitted disease or a termination of pregnancy that had been long forgotten? Would an abused wife really be able to stop her husband accessing her record to find out her history or what she may have said to the doctor about him?

For thousands of years patients have been secure in the knowledge that their doctors would vigorously defend their secrets regardless and that they could safely tell them anything. For some people this is about to end. We have to be very sure that what we gain is worth this loss.

Brian H McKinstry senior researcher

Community Health Sciences: General Practice Section, EdinburghEH89DR brian.mckinstry@blueyonder.co.uk Competing interests: None declared.

1 Richards T. My illness, my record. BMJ 2007;334:510. (10 March.)

\section{It's a catalyst for improvement}

We must not lose sight of the potential of universal patient record access to fundamentally change the quality of consultations. ${ }^{1}$ The key step in any consultation is to reach a shared understanding of the problem with the patient: expectations, hopes, and fears are identified and what can and cannot be done explicitly is discussed and acted on..$^{2}$ In a series of educational assessments of the consultation skills of volunteer experienced UK general practitioners, the most common recommendation for improvement was identifying the patient's reasons for consulting (77\% of participants) ${ }^{3}$ and the fourth most common was collaborating with the patient in agreeing management plans (23\% of participants; unpublished data), vividly demonstrating that the achievement of shared understanding can be improved. When patients can assess the records we make of their consultations, the gap between their agendas and our actions will become explicit and a powerful catalyst for us to improve our consulting skills. Robert K McKinley professor of academic general practice Keele University Medical School, Keele University, Staffordshire ST5 5BG r.k.mckinley@hfac.keele.ac.uk

Richard H Baker professor of quality of health care Department of Health Sciences, University of Leicester, Leicester LE1 6TP

Competing interests: None declared.

1 Richards T. My illness, my record. BMJ 2007;334:510. (10 March.)

2 Fraser A, Skelton J. Royal College of General Practitioners' curriculum statement 2: the general practice consultation. London: RCGP, 2006.

3 McKinley RK, Dean P, Farooqi A. Reactions of volunteer general practitioners to educational assessment of their consultation performance: a qualitative study. Education for Primary Care 2003;14:293-301.

\section{DRUG ELUTING STENTS}

EDITORIAL p 593 and RESEARCH pp 617, 621, 624

\section{What fuels public policy?}

Around $60-75 \%$ of the millions of drug eluting stents inserted globally are not licensed. ${ }^{1}$ What has fuelled the high unlicensed use of a device associated with thrombosis? This question was not dealt with by the Food and Drug Administration panel or recent articles on such stents. ${ }^{2}$ But it is fundamental to public policy issues arising from the extensive off label or unlicensed use of an expensive medical device. A complex interplay of factors may underpin the high use of drug eluting stents beyond an evidence base. These include collaboration between the cardiology 
community and device industry to push new technology, an interventionist community that romanticises new technology, and overdependence on interventionism when treating coronary syndromes. A recent analysis raises concern that the current invasive trendwhich rests on a poor evidence base-is putting financial pressure and stress on healthcare systems that have limited resources. ${ }^{3}$ The factors that fuel the offlicence use of these stents may be part of a larger public policy concern.

A recent editorial on drug eluting stents noted that some common interventionist practices had little empirical justification. It argued that the cost of drug eluting stents is excessive and that that the current conditions for adopting new medical technologies are not necessarily in the public interest. ${ }^{4}$ A related cost effectiveness analysis of these stents suggests that lower quality studies and industry sponsored studies have favoured their widespread use. $^{5}$

Mark H Wilson director of medical ethics health Health Research Associates, Ottawa, Canada K2B 6J4 research@sympatico.ca

Competing interests: None declared.

1 Shuchman M. Debating the risks of drug-eluting stents. NEngl J Med 2007;356:325-8.

2 Drug eluting stents may increase long term mortality due to late stent thrombosis. BMJ 2007;334:390. (24 February.)

3 Bogardy P, Brophy J. Acute ischemic heart disease and interventional cardiology: a time for pause. BMCMed 2006;4:25.

4 Knudtson ML. Drug-eluting coronary stents: faith and hope, but no charity. CMA/ 2007;176:185-90.

5 Ligthart S, Vlemmix F, Dendukuri N, Brophy JM. The cost-effectiveness of drug-eluting stents: a systematic review. CMA/ 2007;176:199-205.

\section{ORGAN DONATION}

\section{Earnest debate is needed}

The growing discrepancy between numbers of patients needing organ transplants and numbers of organs available shows that the current system cannot cope with demand. In the United Kingdom, the waiting list for organ transplants is the highest ever. ${ }^{1}$

The UK laws on organ transplantation evolved as a knee jerk reaction to the sale of Turkish kidneys at a London hospital in 1988-the first Human Organ Transplant Act was rushed through parliament in 1989. The Alder Hey and Bristol sagas of organ retention after autopsies resulted in the Human Tissue Act of 2004. These acts have not helped procurement of organs.

Organ transplantation is the cheapest way to treat end stage kidney disease and offers a better quality of life. If the shortage of organs persists, by 2020 no Western health service will be able to afford dialysis for all patients.

At least 13 European countries have adopted the opt-out (presumed consent) system. ${ }^{2}$ This system fulfils the criteria of autonomy of the individual and organ donations are altruistic. The UK has not enacted such legislation.

But opt-out legislation cannot solve the problem. One solution is to regulate the sale of organs ${ }^{3}$ under the Human Tissue Authority, at least as an experiment.

However, cross border trade should be prohibited. ${ }^{4}$

Rasheed Ahmad emeritus consultant nephrologist Liverpool L25 6DU theahmads@aol.com

Competing interests: None declared.

1 NHS. UK Transplants. Statistics. www.uktransplant.org. uk/ukt/statistics/statistics.jsp.

2 The shortage of organs for transplantation. Where do we go from here? N Engl J Med 1991;325:1245.

3 Griffin A. Kidneys on demand. BMJ 2007;334:502-5 (10 March.)

4 Ahmad R. Rapid response to Anand KP, Kashyap A, Kashyap S. Thinking the unthinkable: selling kidneys. $B M / 2006 ; 333: 149$.

\section{NICE ON CAM}

\section{Appraisals of specific treatments are needed}

In debating whether the National Institute for Health and Clinical Excellence (NICE) should evaluate complementary and alternative medicine (CAM), neither side cites the two recent systematic reviews showing the cost effectiveness of certain treatments in certain conditions. ${ }^{1-4}$

Fourteen exemplary studies indicated that the following CAM therapies may be considered cost effective compared with usual care: acupuncture for people with migraine; manual therapy for people with neck pain; spa therapy for people with Parkinson's disease; self administered stress management for patients with cancer undergoing chemotherapy; preoperative and postoperative oral nutritional supplementation for patients undergoing lower gastrointestinal tract surgery; biofeedback for patients with "functional" disorders such as irritable bowel syndrome; and guided imagery, relaxation therapy, and potassium rich diet for patients with heart disease. ${ }^{34}$ Last year, acupuncture for chronic low back pain was added to the list. ${ }^{5}$ All these interventions are safe and popular with patients. Is it relevant that the only thing they don't do is transform the NHS budget into pharmaceutical company profits?
Charlotte Paterson senior research fellow Institute of Health and Social Care Research, Peninsula Medical School, ExeterEX12LU charlotte.paterson@pms.ac.uk

Competing interests: None declared.

1 Franck L, Chantler C, Dixon M. Should NICE evaluate complementary and alternative medicine? BM] 2007;334:506. (10 March.)

2 Colquhoun D. Should NICE evaluate complementary and alternative medicine? BMJ 2007;334:507. (10 March.)

3 Canter PH, Coon JT, Ernst E. Cost effectiveness of complementary treatments in the United Kingdom: systematic review. BM/ 2005;331:880-1.

4 Herman PM, Craig BM, Caspi O. Is complementary and alternative medicine (CAM) cost-effective? A systematic review. BMC Complement Altern Med 2005;5:11.

5 Wonderling D. Acupuncture in mainstream health care. BMJ 2006;333:611-2.

\section{CERVICAL SPONDYLOSIS}

\section{Dizziness is not diagnostic}

I was dismayed that "dizziness or vertigo" was listed as a presenting feature of cervical spondylosis. ${ }^{1}$ Dizziness is extremely common, especially in elderly people (many of whom have more than one type of dizziness), and it causes considerable morbidity. In nearly all elderly patients, radiography will show a degree of cervical spondylosis. Because most doctors are not trained in dizziness many such patients do not get a proper diagnosis, and the myth of dizziness or vertigo (especially on looking up) due to cervical spondylosis is perpetuated. Many have benign positional vertigo or other treatable diagnoses.

"Dizziness or vertigo due to cervical spondylosis" is generally considered to be a "non-diagnosis" by those who specialise in diagnosing and managing dizziness.

Nicola A Cooper consultant physician Leeds General Infirmary, Leeds LS13EX nacooper@doctors.org.uk Competing interests: None declared.

1 Binder Al. Cervical spondylosis and neck pain. $B M$ 2007;334:527-31. (10 March.)

\section{DRY MOUTH}

\section{Don’t forget diabetes}

There is one glaring omission in the 10 minute consultation on dry mouth: nowhere can I find mention of diabetes. ${ }^{1}$ In my experience, dry mouth is one of the most useful early symptoms of maturity onset diabetes. If a patient complains of a dry mouth I immediately reach for my blood glucose monitor before I start checking for iron overload.

Ian D Rubenstein general practitioner Eagel House Surgery, EnfieldEN34DN prime@eaglehousesurgery.com

Competing interests: None declared.

1 Taubert M, Davies MR, Back I. Dry mouth. BMJ 2007;334:534. (10 March.) 


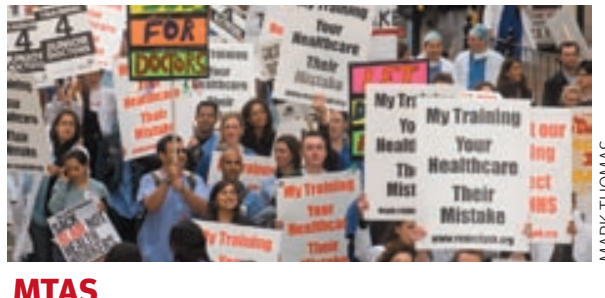

MTAS

See also Lynn Eaton's blog on bmj.com

\section{Good candidates surface in MTAS}

One of the groups I interviewed at the ST1 clinical interview were those whose CVs were good but not outstanding, whose application forms stood out from the rest, and who performed well at interview. ${ }^{1}$

This group's CVs could have ended up in the shredder under the old system but they do well under the new. Undoubtedly the academics will want greater credence placed on British first class honours degrees next time around, but I would be sad if we throw away the chance of recruiting this group in any reform. After all, most of our successful applicants will not be leading a research team or even be working in an academic unit. Is a first class honours degree a reliable predictor of clinical and professional excellence? Is it purely a function of the individual unrelated to the BA or BSc project or supervisor?

Colin Borland consultant physician, Hinchingbrooke Hospital, Huntingdon PE28 4TW colin.borland@hinchingbrooke.nhs.uk Competing interests: None declared.

1 Coombes R. How specialist training reform sparked crisis of confidence. BMJ 2007;334:508-9. (10 March.)

\section{"Tell me the positives of MTAS"}

Last week in my 15 minute interview for an ST2 post in anaesthesia, I was asked three MMC enforced questions, no more, no less. ${ }^{1}$ My portfolio was not opened, and my CV not looked at.

(1) How has your last year in anaesthesia lived up to expectations?

(2) Why do you want to work in this region?

(3) Tell me the positives of MTAS (medical training application system).

How this interview allowed anyone to differentiate between who is safe and competent to deliver an anaesthetic and continue training is totally beyond me. These questions were stipulated by MMC (Modernising Medical Careers) and supplied with their own marking scheme. It seems doctors are being appointed on their ability to toe the party line.

Natalie M Green senior house officer anaesthesia, University Hospital, Aintree, Liverpool L97AL indiakate@hotmail.com Competing interests: None declared.

1 Brown MJ, et al. Raging against MTAS. BMJ 2007 Mar 7. www.bmj.com/cgi/eletters/333/7579/0-f\#161670.

\section{Interview lacked depth}

At my ST2 interview no plastic surgeon was present, and no interest was taken in my thesis, log book, current job, career aspirations, publications, book, or medical patents. ${ }^{1}$

Akbar de' Medici senior house officer, plastic surgery Royal Free and Mount Vernon Hospitals akbar@medisilva.co.uk Competing interests: None declared.

1 Brown MJ, et al. Raging against MTAS. BMJ 2007 Mar 7. www.bmj.com/cgi/eletters/333/7579/0-f\#161670.

\section{In defence of MMC and MTAS}

The MTAS (medical training application system) process was called for and designed with the help of junior doctors. ${ }^{1}$ The pseudo-anonymised form and separate individuals scoring individual elementsrather than whole $\mathrm{CVs}$-are sensible ways of preventing the rampant discrimination prevalent in the old system. The use of 150 word answers to questions about clinical practice and attitudes rather than just relying on qualifications and publications was a response to requests from junior doctors to stop the early years of training becoming a mad scrabble to gain ever more postgraduate diplomas and to publish papers at the expense of enjoying learning clinical medicine.

Simon J A Eccles consultant in emergency medicine Homerton University Hospital, London E9 6SR simon.eccles@nhs.net

Competing interests: SJAE was chairman of the BMA Junior Doctors Committee from September 2003 until August 2005.

1 Coombes R. How specialist training reform sparked crisis of confidence. BMJ 2007;334:508-9. (10 March.) PublicationsPolicyAndGuidance/DH_4086975.

\section{How can we cure MTAS?}

MTAS could be modified so that everyone who achieves the essential criteria is offered an interview for their first choice application. ${ }^{1}$ The other candidates interviewed in each area would be determined by shortlist scoring. This rule would ensure that virtually all trainees were considered for at least one post in the first round and that most interviewees would want the post they were being interviewed for. It would clearly give preference to certain candidates in each area, but if it were applied nationally everyone would obtain the same benefit.

Peter D Macdonald consultant paediatrician Southern General Hospital, Glasgow G51 4TF peter.macdonald@sgh.scot.nhs.uk

Competing interests: PDM is a member of $\mathrm{O}$ and $\mathrm{G}$ and Paediatric Transitional Board (Scotland).

1 Coombes R. How specialist training reform sparked crisis of confidence. BMJ 2007;334:508-9. (10 March.)

\section{Equality, transparency, fairness for all}

When non-UK doctors were recruited by the NHS the prospects of equal opportunities were offered. Non-UK doctors employed in training positions therefore assumed natural progression to more senior positions on the basis of merit and experience. Why should they be barred from competing for more senior positions once they have obtained further qualifications and competencies? ${ }^{1}$

We need to aim for a system that is fair, equitable, and transparent in which all current trainees in the NHS can compete on the basis of their qualifications, competencies, and references. Falling victim to divide and rule politics is perhaps the biggest mistake the medical fraternity can now make.

JT George specialist registrar in diabetes, endocrinology, and general (internal) medicine York Hospital, York YO31 8HE dritgeorge@yahoo.co.uk

Kavitha S Rozario senior staff practitioner in paediatrics Harrogate District Hospital, Harrogate HG2 7SX Competing interests: None declared.

1 Brown MJ, et al. Raging against MTAS. BMJ 2007 Mar 7. www.bmj.com/cgi/eletters/333/7579/0-f\#161670.

\section{Unite to stop divide and rule}

The government's promise to deliver a consultant led NHS has been replaced by an MMC ladder with the original consultant post at the pinnacle being mysteriously replaced with the uninterpretable senior medical appointment. A disingenuous MMC plan coupled with the policy of expanding medical school intake to provide more trained doctors has been exposed as a calculated method to manufacture unemployment, thus giving the government political control over clinicians, at the same time providing the tool to drive down wages while creating service-providing clinicians with minimal potential for career development. At long last we as a profession are beginning to realise that we must come together to prevent the attempts by the government and its political pawns to divide and conquer. ${ }^{1}$

Andrew Clegg specialist registrar, geriatrics Yorkshire Deanery, Leeds LS2 9JT andrewpaulclegg@yahoo.co.uk Competing interests: None declared.

1 Brown MJ, et al. Raging against MTAS. BMJ 2007 Mar www.bmj.com/cgi/eletters/333/7579/0-f\#161670. 